\title{
Problem of Home-Care Waste Recovery at Home-Visit Nursing Stations in Japan
}

\author{
Yukihiro Ikeda*
}

\author{
Center for Occupational Safety and Health Management, Kinki University Hospital, Japan
}

\begin{abstract}
A questionnaire survey was conducted to investigate the problems involved in the infectious waste recovery at home-visit nursing stations. 1965 nursing stations were selected randomly, and questionnaires were sent to them. Nurses at 1314 stations $(66.9 \%)$ responded to the survey and responses from 1283 stations were identified as suitable for analysis after excluding 26 stations that closed and five stations whose main field of care was psychiatry. Nursing stations using an automobile mainly were classified as "Auto stations" and all others were classified as "non-Auto stations". Auto station nurses were more concerned with bad odor from waste. Non-Auto station nurses were more concerned with the physical weight of transported waste. Thus, in order to alleviate these concerns, it is necessary to provide nurses with containers for medical waste suited to home-visit nursing care and tools for preventing injuries.
\end{abstract}

Keywords: Home-visit nursing, home-care waste management, medical waste, occupational safety.

\section{INTRODUCTION}

Recently, home medical care (HMC) services have become more prominent and widespread in Japan with 5500 registered and about 1500 unregistered HMC stations currently in operation. About half of the HMC stations are affiliated to hospitals [1]. Domestic medical waste is a constant concern and growing problem with HMC. The Japanese Waste Disposal and Public Cleansing Law classifies waste materials as either industrial waste or general household/municipal waste [2]. Industrial waste results from industrial activities and general waste is all other waste not produced by industries (Fig. 1). Infectious waste such as bloody bandages, body swab or cotton wool from hospitals or clinics is classified as industrial waste with special control [3]. Mechanical hazard such as surgeon's knife, needle or broken glasses from hospitals or clinics is also classified as industrial waste with special control [3]. Chemical waste such as dialysis fluid or antiseptic solution are also classified as industrial waste with special control [3]. However, HMC waste such as infusion bag, needles, cotton wool with blood and antiseptic solution are classified as general waste with special control. Municipalities are responsible for disposal of general waste which contains these HMC waste. However, many municipalities do not collect some or all HMC waste due to fears of infection or sharp [4-6]. Home-visit nurses often collect HMC waste that is not collected by municipalities and the safety of such waste is left to the care of the nurses. There have been few studies on occupational injuries resulting from HMC waste collection. In addition, these studies are small number of samples [6-10] and there is a bias in the region [7-9] or low response rate [8]. The purpose of this study is to investigate the current burdens placed on home-visit nurses in regards to $\mathrm{HMC}$ waste collection and to identify specific problems.

*Address correspondence to this author at the Center for Occupational Safety and Health Management, Kinki University Hospital, 377-2 Oonohigashi Osakasayama, Osaka, 589-8511, Japan; Tel: +81-72-366-0221; Fax:+81-72-220-7113; E-mail: yuyu@med.kindai.ac.jp

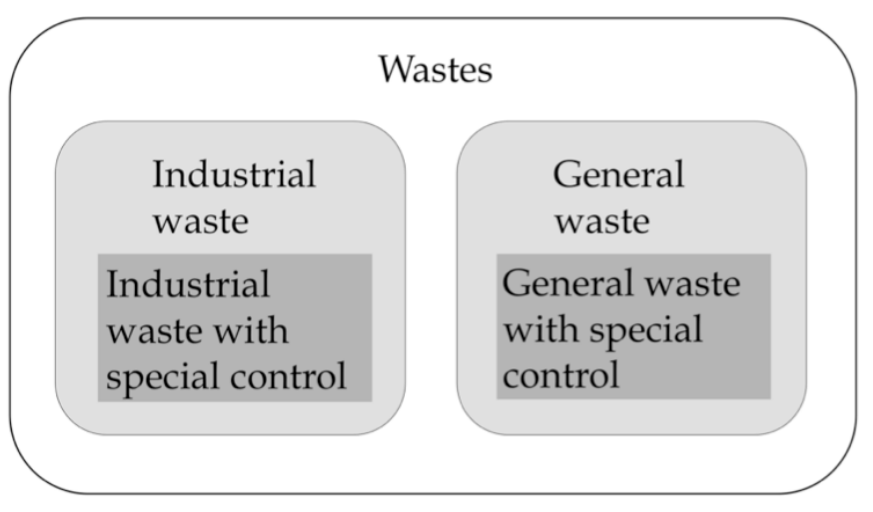

Fig. (1). Classfication of waste under Japanese law.

\section{SUBJECTS AND METHODS}

To determine current practices in the disposal and handling of HMC waste, a questionnaire was formulated and mailed to 1965 offices nationwide in 2009. Questionnaire was mainly a selection formula. The choices were created with reference to previous studies [7, 8]. All 1965 home-visiting nursing offices were randomly selected from the list provided by the National Association for Home-Visit Nursing Care. A nurse who represented the nursing station was answered the questionnaire. After collection, the questionnaire was converted into electronic format and provided to the subjects of the study. Statistical data analyses were conducted using SPSS $^{\circledR}$ statistics software. Continuous parameters with normal distribution were analyzed by Student's $t$-test. Three-point scales with non-normally distributed variables were analyzed with the Mann-Whitney Utest. Binary variables were analyzed by the chi-square test. A two-tailed test was used for all statistical analyses. In all cases, a $p$ value of 0.05 was used as the threshold level of significance.

\section{RESULTS}

\section{Basic Characteristics of the Subjects}

Nurses represented each 1314 stations replied to the questionnaire, 651 stations did not reply, and 26 stations 
closed down. Five stations performed only psychiatric services and thus did not dispose of HMC waste. Analysis of the remaining 1283 stations was made. Stations were classified by means of a visit. Nursing stations using an automobile mainly were classified as "Auto stations" and all others were classified as "non-Auto stations" (Table 1). On average, Auto stations had been in existence longer than Non-auto stations $(p<0.05)$. In addition, Non-auto stations have fewer part-time nurses and visit patients' houses less often per month than do Auto stations (Table 1).

Table 1. Basic Station Characteristics ${ }^{1}$

\begin{tabular}{|c|c|c|}
\hline & $\begin{array}{c}\text { Auto Station } \\
(\mathbf{n}=1143)\end{array}$ & $\begin{array}{c}\text { Non-Auto Station } \\
(\mathbf{n}=\mathbf{1 4 0})\end{array}$ \\
\hline \hline Opening year* & $1998.7 \pm 0.1$ & $1999.6 \pm 0.4$ \\
\hline Full-time nurse & $3.8 \pm 0.1$ & $3.8 \pm 0.1$ \\
\hline Part-time nurse & $2.9 \pm 0.1$ & $2.5 \pm 0.2$ \\
\hline $\begin{array}{c}\text { Number of home } \\
\text { visits per month }\end{array}$ & $372.9 \pm 7.3$ & $395.8 \pm 17.7$ \\
\hline \multicolumn{2}{|l|}{ Values are means \pm SE; $* \mathrm{p}<0.05$, significant differences between two station groups. }
\end{tabular}

\section{Waste Recovery Status and Problems}

More Auto station nurses recovered medical waste from patients' homes than did Non-auto station nurses $(p<0.01$, Table 2). They were more concerned about getting injured by the waste. They also worried about bad odor from waste $(\mathrm{p}<0.001$, Table 2$)$. On the other hand, Non-auto station nurses were more worried about the physical weight of transported waste $(\mathrm{p}<0.001$, Table 2$)$.

\section{Improvement of HMC Waste Disposal}

There are five terms about HMC waste disposal shown in Table 3. Each terms were listed in the questionnaire with reference to previous studies $[7,8]$ and nurses chose the answer in the form of three points scale. Nurses had higher scores in the handling of medical waste on visit or waste treatment container. There was not a significant difference between Auto and Non-auto stations.

\section{DISCUSSION}

The present study outlines the current status of HMC waste recovery and identifies the most pressing problems encountered by home-visit nurses. Many visiting nurses have to recover HMC waste from patients' houses and return it to their stations for disposal. In this study, $80.4 \%$ of nurses visited by auto and $70.7 \%$ of nurses visited by non-auto (79.3\% of nurses in total) transport HMC waste from patients' houses to their stations. Because of differences in the amount of logistical barriers, nurses working at Auto stations recover HMC waste and deliver it to their stations more easily than do nurses visiting by non-Auto stations. Thus, the waste recovery rate was higher for Auto stations. The waste recovery rate was studied in a previous study [5], which found that $61.2 \%$ of home-visit nursing stations recover HMC waste; however, this study did not shown the waste recovery rate by a visit, so this is the first study to state waste recovery rate by a visit.

Some HMC waste is not infectious such as dialysis bag, tube, and plastic bottle. It is appropriate that these noninfectious wastes are being treated as general waste. In this regard, some Japanese municipalities provide a guide to be treated as general waste to these non-infectious wastes.

Table 2. Waste Recovery Status and Problems

\begin{tabular}{|l|c|c|}
\hline & Auto Station (n=1143) & Non-Auto Station (n=140) \\
\hline \hline Nurses carrys the home care waste from patient's home to their station.** & $920(80.4)$ & $99(70.7)$ \\
\hline Nurses have to go visit the next home along with the waste.. & $512(44.8)$ & $67(47.9)$ \\
\hline Nurses are afraid of getting injured by the waste. & $343(30.0)$ & $31(22.1)$ \\
\hline Nurses worry about bad odor from waste.*** & $341(29.8)$ & $15(10.7)$ \\
\hline Nurses worry about heavy waste.*** & $28(2.4)$ & $11(7.9)$ \\
\hline
\end{tabular}

Values are observation and (percent in each category); ${ }^{* * *} \mathrm{p}<0.001,{ }^{* *} \mathrm{p}<0.01$, significant differences between two station groups.

Table 3. Improvement in Home Medical Care Waste Disposal ${ }^{1}$

\begin{tabular}{|c|c|c|c|c|c|c|}
\hline \multirow{2}{*}{} & \multicolumn{3}{|c|}{ Auto Station (n=1143) } & \multicolumn{3}{c|}{ Non-Auto Station (n=140) } \\
\cline { 2 - 6 } & Important & Moderate & Not Important & Important & Moderate & Not Important \\
\hline \hline Waste treatment container & $979(85.7)$ & $122(10.7)$ & $24(2.1)$ & $114(81.4)$ & $21(15.0)$ & $2(1.4)$ \\
\hline Handling of medical waste on visit & $1032(90.3)$ & $79(6.9)$ & $11(1.0)$ & $125(89.3)$ & $12(8.6)$ & $1(0.7)$ \\
\hline Burden of expense for waste disposal & $731(64.0)$ & $297(26.0)$ & $76(6.6)$ & $85(60.7)$ & $37(26.4)$ & $9(6.4)$ \\
\hline Handling of medical waste at station & $858(75.1)$ & $190(16.6)$ & $46(4.0)$ & $98(70.0)$ & $30(21.4)$ & $3(2.1)$ \\
\hline Confirmation of final waste disposal & $682(59.7)$ & $337(29.5)$ & $65(5.7)$ & $83(59.3)$ & $45(32.1)$ & $8(5.7)$ \\
\hline
\end{tabular}

Values are observation and (percent in each category). 
However, some home patients do not want to take out these waste as general waste, because the patient is afraid that it known to others of their disease. Such non infectious HMC wastes were collected by nurses. Some home patients also take these wastes to their doctors. Education to home patients is also important issues. Thus, current Japanese system has many problems. Home care is increasing every year and is a viable alternative to hospitalization for many patients. Fundamental reform is needed.

The main problem is that HMC waste has been classified as general waste [3]. Because of the law, municipal workers are responsible for dispose HMC waste. However, municipal workers have had a difficult time keeping abreast of the medical knowledge required for the proper handling of HMC waste [6]. Thus, it would seem that placing a greater burden for waste recovery on trained medical professionals is not unwarranted. Even then, a recent study showed $66 \%$ of municipalities recover HMC waste as a domestic waste [10]. Waste recovery seems to proceed slowly in Japanese municipalities. In this vein, the World Health Organization and the U.S. Environmental Protection Agency have already established strict guidelines for the management of infectious waste from medical institutions [11-14]. In the U.S., but slightly different by the state, classification of waste is determined only by the hazard. In New York State as an example, HMC wastes are classified into three, that is, Human Pathological Wastes, Human Blood and Blood Products, Sharps [15]. On the other hand, in Japan, waste has been classified by place of occurrence [3]. This is the biggest difference. Therefore, many problems with HMC waste disposal in Japan can be resolved by changing the law. It is time for the Japanese government to address HMC waste disposal more comprehensively through necessary legislation and standardization. In this respect, Japanese ministry of Environment launched the guideline for HMC waste disposal finally [16]. Moreover, most nurses $(90.3 \%$ of Auto station nurses and $89.3 \%$ of non-Auto station nurses shown in Table 3) were concerned with handling of medical waste on visit. There is nomanual for disposal of HMC waste in Japan yet. Most nurses need a manual for disposal of HMC waste and the Japanese government should propose a manual for disposal of HMC waste. To help lay the foundation for future action on HMC waste carrying, this study identified several key characteristics of HMC waste carrying by home-visit nurses. First, $44.8 \%$ of nurses working at Auto stations and $47.9 \%$ of nurses working at non-Auto stations must carry waste with them after their first home visit on a given day. In addition, Auto station nurses also worry about bad odor, especially because autos are the most commonly used means of transportation for home visits as they are useful in carrying multiple items and supplies. The Japanese government should help facilitate carrying of HMC by subsidizing the compartmentalization of the autos used by home-visit nurses to help control odor problems and alleviate fears of contamination. On the other hand, because some of home-visit nurses use bicycles and there are many narrow roads in Japan, especially in urban areas, small storage and transport devices for waste that are suitable for bicycle visits are also needed.

The present study had several advantages over previous studies [5-10] with respect to study design. First, data were collected from a larger nation wide sample of home-visit nursing stations. A large number of the stations in this study were opened in the 1990s, especially after 1995, which coincides with the boom in home-visit nurse stations in Japan [1]. In addition, by incorporating the newer stations, the sample was made more representative of the general HMC station. Second, despite the nationwide survey, the response rate of this study was $66.9 \%$. This was good response rate. However, its limitations must not be overlooked. First, because the subjects surveyed were only home-visit nursing stations, no conclusions can be drawn about any other services involved with HMC waste disposal, such as municipalities, other waste disposers, and medical institutions. Second, the current study does not adequately address the disparate situations faced by nurses in a variety of regional and management configurations. These additional questions and considerations, among others, should be the focus of future studies.

\section{CONCLUSIONS}

Domestic medical waste is a constant concern and growing problem with HMC. Home-visit nurses felt a great burden of HMC waste management. It is time for the Japanese government to address HMC waste disposal more comprehensively through necessary legislation, education, technical changes to transportation, and standardization.

\section{ACKNOWLEDGEMENTS}

This study was supported by the Japan Ministry of the Environment (grant-in-aid for scientific research to promote a recycling-oriented society $08065604,2008-2010$ ).

\section{CONFLICT OF INTEREST}

None declared.

\section{REFERENCES}

[1] Japan ministry of health labor and welfare statistics. "Summary of survey results nursing care facilities business" (in Japanese). Reference available from: http:/www.mhlw.go.jp/toukei/saikin/ hw/kaigo/service09/index.html [Accessed Feb. 28, 2012].

[2] Japan ministry of the Environment. Japanese waste disposal and public cleansing law. No. 66 of 2001 (in Japanese). Reference available from: http://law.e-gov.go.jp/htmldata/S45/S45HO137. html [Accessed Feb. 28, 2012].

[3] S. Naito, "Hazardous wastes management in Japan." In: International Perspectives on Hazardous Waste Management. Forester, W.A., Skinner, J.H. Eds. Academic Press: London, 1987, pp. 161188.

[4] Japan Ministry of the Environment. "Study Report on the Home Health Care Waste handling" (in Japanese). Reference available from: http://www.env.go.jp/recycle/report/h17-03/index.html [Accessed Mar. 2, 2012].

[5] M. Miyazaki, T. Imatoh, H. Une, "The treatment of infectious waste arising from home health and medical care services: Present situation in Japan." Waste Manag., vol. 27, pp. 130-134, 2007.

[6] M. Harada, "Municipalities activity support on medical waste" (in Japanese). Yugai Iryohaikibutu Kenkyu, vol. 20, pp. 3-11, 2007.

[7] H. Yano, M. Shirai, C. Ishiguro, H. Mori, E. Hirai, N. Sasaki, Y. Hirose, H. Matsushima, "Education support for home care and proper disposal of waste in home-visit nursing station" (in Japanese), Iryohaikibutu Kenkyu, vol. 15, pp. 17-31, 2002.

[8] K. Sugihara, T. Tayama, K. Nishimura, S. Ohta, "Survey and collection and disposal of home medical waste in Hiroshima Prefecture" (in Japanese). Yugai Iryohaikibutu Kenkyu, vol. 21, pp. 78-84, 2009.

[9] E. Hirai, R. Muraoka, A. Nozawa, H. Yano, K. Kodama, H. Matsushima, "Current Status and Issues on the handling of medical waste in-home visit nursing care stations in Shizuoka Prefecture" (in Japanese). Iryohaikibutu Kenkyu, vol. 14, pp. 27-37, 2001. 
[10] M. Harada, "The points of appropriate treatment for home medical care waste" (in Japanese). Yugai Iryohaikibutu Kenkyu, vol. 23, pp. $78-84,2011$

[11] World Health Organization, regional office for western pacific and for south-east pacific, "Practical guidelines for infection control in health care facilities", Reference available from: whqlibdoc.who. int/wpro/2003/a82694.pdf' [Accessed Feb. 28, 2012].

[12] Environmental Protection Agency, "EPA guide for infectious waste management." Environmental Protection Agency. Reference available from: $\mathrm{http}: / /$ nepis.epa.gov/Exe/ZyPURL.cgi?Dockey=200 0E1HP.txt [Accessed Feb. 28, 2012].

[13] V. J. Landrum, R. G. Barton, Medical waste management and disposal. Pollution Technology Review No 200. William Andrew Publishing: USA, 1991.
[14] Department of Health/Finance and Investment Directoratge/Estatesand Facilities Division, "Health Technical Memorandum 07-01 Safe Management of Healthcare Waste.”, Quarry House Leeds LS2 7UE. Reference available from: http://www.dh.gov.uk/en/Public ationsandstatistics/Publications/PublicationsPolicyAndGuidance/D H_063274 [Accessed Feb. 28, 2012].

[15] New York State department of health, "Managing Regulated Medical Waste", Reference available from: http://www.health.ny. gov/facilities/waste/ [Accessed Feb. 29, 2012].

[16] Japan Ministry of the Environment "The guideline for home medical care waste management and disposal" (in Japanese) Reference available form: http://www.env.go.jp/recycle/misc/ guideline.html [Accessed Feb. 28, 2012].

Received: January 27, 2012

Revised: March 10,2012

Accepted: March 10, 2012

(C) Yukihiro Ikeda; Licensee Bentham Open.

This is an open access article licensed under the terms of the Creative Commons Attribution Non-Commercial License (http://creativecommons.org/licenses/by$\mathrm{nc} / 3.0 /$ ) which permits unrestricted, non-commercial use, distribution and reproduction in any medium, provided the work is properly cited. 